\title{
The interaction of Akkermansia muciniphila with host-derived substances, bacteria and diets
}

\author{
Tatsuro Hagi ${ }^{1}$ (D) $\cdot$ Clara Belzer $^{2}$
}

Received: 18 March 2021 / Revised: 11 May 2021 / Accepted: 20 May 2021 / Published online: 14 June 2021

(C) The Author(s) 2021

\begin{abstract}
Trillions of microbes inhabit the human gut and build extremely complex communities. Gut microbes contribute to host metabolisms for better or worse and are widely studied and associated with health and disease. Akkermansia muciniphila is a gut microbiota member, which uses mucin as both carbon and nitrogen sources. Many studies on A. muciniphila have been conducted since this unique bacterium was first described in 2004. A. muciniphila can play an important role in our health because of its beneficial effects, such as improving type II diabetes and obesity and anti-inflammation. A. muciniphila establishes its position as a next-generation probiotic. Besides the effect of $A$. muciniphila on host health, a technique for boosting has been investigated. In this review, we show what factors can modulate the abundance of A. muciniphila focusing on the interaction with host-derived substances, other bacteria and diets. This review also refers to the possibility of the interaction between medicine and A. muciniphila; this will open up future treatment strategies that can increase A. muciniphila abundance in the gut.
\end{abstract}

\section{Key points}

- Host-derived substances such as bile, microRNA and melatonin as well as mucin have beneficial effects on A. muciniphila.

- Gut and probiotic bacteria and diet ingredients such as carbohydrates and phytochemicals could boost the abundance of A. muciniphila.

- Several medicines could affect the growth of A. muciniphila.

Keywords Akkermansia muciniphila $\cdot$ Bile acid $\cdot$ Diet $\cdot$ Gut bacteria $\cdot$ Host-derived substances $\cdot$ Prebiotic $\cdot$ Medicine

\section{Introduction}

Beneficial microbes, probiotics such as bifidobacteria and lactic acid bacteria, can sustain or improve host health by producing antimicrobial substances, immunomodulation and competition for adhesion to host cells with pathogens (Servin 2004). Commensal gut bacteria also can sustain host health. Short-chain fatty acids (SCFAs) such as propionate

Tatsuro Hagi

thagi@affrc.go.jp

$\triangle$ Clara Belzer

clara.belzer@wur.nl

1 Institute of Livestock and Grassland Science, National Agriculture and Food Research Organisation (NARO), 2 Ikenodai, Tsukuba, Ibaraki 305-0901, Japan

2 Laboratory of Microbiology, Wageningen University and Research, 6708 WE Wageningen, The Netherlands and butyrate, produced by commensal gut bacteria such as Bacteroidetes, Firmicutes, Actinobacteria and Verrucomicrobia, are used as a source of energy and immunomodulation in the host (Louis and Flint 2017). In return for these effects or to foster gut bacteria, substances such as mucin, maternal milk and bile, which can all be growth factors for bacteria in the gut, are provided by the host (Aakko et al. 2017; McLoughlin et al. 2016; Wahlström et al. 2016). Mucin is an energy source for mucin-degrading bacteria such as Bacteroides and Akkermansia (Crouch et al. 2020). Bile acids strongly link host physiology with bacterial metabolism. Primary bile acids are secreted to the gut by the liver for the absorption of lipid from diets, and primary bile acids are converted to secondary bile acids by a part of gut bacteria (Wahlström et al. 2016). Bile metabolism can modulate gut microbiota maturation (van Best et al. 2020). Human oligosaccharides (HMOs) in maternal milk are among the most important factors to modulate gut bacteria (Lawson et al. 2020). A part of gut bacteria such as members of the genus 
Bifidobacterium, Bacteroides and Akkermansia muciniphila have specific enzymes to use HMO (Aakko et al. 2017; Kostopoulos et al. 2020). Conversely, diets and antibiotics also affect gut microbiota (Gentile and Weir 2018; Mu and $\mathrm{Zhu}$ 2019). Ingredients of diets such as fibre and fat or foods such as fermented milk can modulate gut microbiota (Daniel et al. 2014; Makki et al. 2018; Veiga et al. 2014). Diet can also alter human gut microbiota reproducibly (David et al. 2014).

Gut bacteria can strongly affect host systems involved in homeostasis such as metabolism and the central nervous and immune systems (Marchesi et al. 2016; Rutsch et al. 2020). Concerning the immune-metabolic axis, gut bacteria are associated with metabolic disorders such as obesity and type II diabetes (Dabke et al. 2019). In the brain-gut axis, multiple sclerosis and Alzheimer's diseases are strongly correlated with gut microbiota (Chen et al. 2016; Vogt et al. 2017). Gut microbiota is also associated with blood glucose regulation via enteric neurons (Muller et al. 2020). From a comparison study of gut microbiota between healthy volunteers and patients, gut bacteria associated with host health such as Akkermansia muciniphila (improvement of metabolic disorder) have been reported (Depommier et al. 2019; Everard et al. 2013; Plovier et al. 2017). That is why gut microbiota is recognised as a superorgan in the human body (Putignani et al. 2014). It is of interest to understand how gut bacteria interact with human health and how the gut stimulates beneficial bacteria that inhabit a gut.

A. muciniphila, isolated from human faeces, can degrade mucin and use it as a sole carbon and nitrogen source (Derrien et al. 2004). The abundance of A. muciniphila is inversely associated with obesity, diabetes and inflammation (Hansen et al. 2012; Santacruz et al. 2010; Schneeberger et al. 2015). The reverse effect of $A$. muciniphila on obesity and diabetes is becoming clear by animal and human studies (Depommier et al. 2019; Plovier et al. 2017). A. muciniphila can also induce host adaptive immune response (Ansaldo et al. 2019). These studies make A. muciniphila a next-generation beneficial microbe. Hence, our health needs to stimulate A. muciniphila in the gut. This review gives an update on current knowledge of the stimulation factor of $A$. muciniphila. The effect of hostderived substance, bacteria and diets on the change in the gut microbial niche of $A$. muciniphila is reviewed.

\section{Interaction with host-derived substances}

Carbon and nitrogen sources are the most important nutrients for microbes and those that reside in the gut environment. Figure 1 illustrates the important host-derived substances for A. muciniphila. Mucin is the most important substance for mucin-degrading bacterium A. muciniphila (Ottman et al. 2017). Administration of mucin stimulates A. muciniphila, so that $A$. muciniphila prefers mucin to other sugar such as

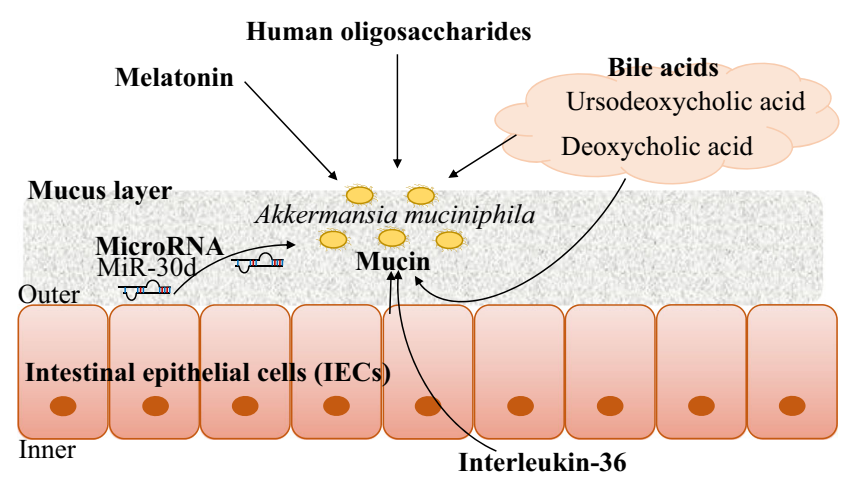

Fig. 1 The host-derived substances modulate A. muciniphila

glucose and mannose (Berry et al. 2015). Especially, $A$. muciniphila may prefer sulfated mucin because the higher percentage of sulfated mucin is positively associated with the abundance of $A$. muciniphila (Earley et al. 2019). On the mucus layer, oxygen is diffused from intestinal epithelial cells (IECs). A. muciniphila also adapts to oxic-anoxic interface using cytochrome system (Ouwerkerk et al. 2016). The interaction between $A$. muciniphila and mucin has been reviewed in more detail (Geerlings et al. 2018). Mucin is secreted by IECs. IECs are key cells of gut bacteria interaction because of their gut homeostasis functions such as mucosal barriers and immunological mediators (Wittkopf et al. 2014). There is a unique substance derived from IECs, which can stimulate the growth of A. muciniphila, 'microRNA'.

IECs and other cells such as immune cells, adipocytes and other epithelial cells produce microRNAs. MicroRNAs are small non-coding RNAs, a class of endogenous RNAs with 21-25 nucleotides (O'Brien et al. 2018). MicroRNAs are observed in the faecal samples and body fluids such as serum, milk and saliva (Duran-Sanchon et al. 2020; Gallo et al. 2012; Kroh et al. 2010; Mirza et al. 2019). The host's gene expression and the gut microbiota are regulated by microRNAs (Gennarino et al. 2009). The disturbance of gut microbiota composition is observed in IEC microRNA-deficient mice (Liu et al. 2016). MiR-515-5p and miR-1226-5p can affect the growth of Fusobacterium nucleatum and Escherichia coli, respectively. In the case of $A$. muciniphila, oral administration of miR-30d to mice affects this microorganism's physiology by regulating the expression of gene encoding lactase of $A$. muciniphila leading to the bloom of A. muciniphila (Liu et al. 2019). Different microRNAs have a specific effect on each gut bacteria. Further study on the interaction between microRNA and gut bacterial species could lead to innovative techniques for modulating the gut microbiota's targeted microorganisms.

Breast milk can modulate gut microbial composition at an early life stage (Moossavi et al. 2019). Here breast milk is defined as physiological substances because it contains sugar (oligosaccharides), proteins, vitamins, hormones, cytokines and even bacteria (Ballard and Morrow 2013; Moossavi 
et al. 2019). Concerning the effect of breast milk on gut bacteria, HMOs are well known to stimulate Bifidobacterium spp. (Lawson et al. 2020). Although the abundance of Bifidobacterium spp. in the breast-fed infants was higher than that in formula-fed infants, the lower abundance of $A$. muciniphila was observed in breast-fed infants (Bergström et al. 2014). Interestingly, A. muciniphila can use HMOs (Kostopoulos et al. 2020). Dual hydroxylation of glycan in mucin and breast milk may confer an ability for getting a niche in the gut mucosal environment to A. muciniphila. Goat milk also could increase the population of A. muciniphila in mice although the mechanism is unknown (Kao et al. 2020).

The comparison study on the interaction between metabolic disorder and microbiome newly demonstrates the effect of hormone and cytokine on the abundance of A. muciniphila. Melatonin, known as a sleep-promoting hormone secreted by the enigmatic pineal gland (Pandi-Perumal et al. 2005), prevents obesity via gut microbiota in high-fat-fed mice (Xu et al. 2017). This study also shows that melatonin treatment could increase the abundance of genus Akkermansia. The abundance of A. muciniphila is regulated by interleukin-36 (IL36) cytokine (Giannoudaki et al. 2019). The knockout of IL36 receptor antagonist, known to inhibit the effect of IL-36, can cause an increase in mucin production leading to the abundance of A. muciniphila and the reduction of weight gain and metabolic dysfunction in mice.

Bile metabolism is strongly associated with gut microbiota because primary bile acids secreted by the host are converted to secondary bile acids by gut bacteria-harbouring bile modification enzymes associated with bile hydroxylation and deconjugation (Wahlström et al. 2016). The growth of $A$. muciniphila is increased by a secondary bile acid (deoxycholic acid (DCA)) (Hagi et al. 2020). DCA also increases the expression of MUC2 in human colon carcinoma cells (Song et al. 2005). Another bile acid, ursodeoxycholic acid (UDCA), can increase the abundance of A. muciniphila in mice (Van den Bossche et al. 2017). Secondary bile acid may be a key bile acid for A. muciniphila to survive in the gut. A part of the bile acid-resistant mechanism in A. muciniphila has been clear (Hagi et al. 2020). Transcriptomic analysis showed that the treatment of ox-bile upregulated the expression of genes encoding HlyD (membrane fusion protein)-ABC and RND (resistance-nodulation-cell division protein family) type transporters. An ABC transporter inhibitor (orthovanadate) and RND-type transporter inhibitor (Pa $\beta N$ (Phe-Arg $\beta$ naphthylamide dihydrochloride)) could reduce the tolerance against bile acids. These transporters play an important role in the bile acid tolerance of A. muciniphila.

The suppressed gastric acid production by proton pump inhibitor (PPI) can alter gut bacterial composition in humans (Jackson et al. 2016). PPIs might weaken a barrier of gastric acid to protect bacterial invasion from the external environment. Interestingly, PPI use is also positively associated with the high-fat mass index and negative abundance of $A$. muciniphila (Davis et al. 2020). However, whether IPPs could affect the change in abundance of A. muciniphila directly is unclear. Another medicine, metformin used in the treatment of type 2 diabetes, affected the increased population and change in gene expression of A. muciniphila (Shin et al. 2014; Wu et al. 2017). The change in gut microbiota by metformin may be associated with host homeostasis because the level of bile acids in plasma and SCFAs in faeces could be increased by metformin. Medicines used for metabolic syndrome could affect A. muciniphila via a change in host metabolism such as bile acids although the detailed mechanisms are unknown. These results imply that the impact of transporter inhibitors on commensal gut microbiota including A. muciniphila needs to be investigated for our health.

\section{Interaction with bacteria}

Various gut bacteria such as A. muciniphila inhabit the mucus layer and interact with each other. Figure 2 illustrates the interplay between A. muciniphila and other bacteria. Some bacteria cannot degrade mucin, so non-mucin-degrading bacteria benefit from mucin-degrading bacteria. A. muciniphila produces sugars derived from mucus and SCFAs such as acetate and propionate. Non-mucus-degrading bacteria such as Anaerostipes caccae, Eubacterium hallii and Faecalibacterium prausnitzii use sugars degraded from mucin by A. muciniphila for their growth. The growth of A.caccae and butyrate production was supported by mucin degradation of A. muciniphila (Chia et al. 2018). Interestingly, A. caccae induces the increased expression of mucin degradation genes and reduced expression of ribosomal genes in A. muciniphila. In another bacterial interaction, 1,2-propanediol produced by A. muciniphila is used by E. hallii for the production of propionate. In return for sugars and SCFA, pseudovitamin B12 required for propionate metabolism is given by $E$. hallii (Belzer et al. 2017). A. muciniphila also has a cobamide remodelling enzyme CbiR (Mok et al. 2020). In the presence of a vitamin $\mathrm{B} 12$ analogue cobinamide, A. muciniphila can produce pseudovitamin B12 using CbiR. Another study shows that another A. muciniphila strain could produce vitamin B12 (ATTC BAA-835 strain cannot synthesise) although vitamin B12 from others promoted propionate production (Kirmiz et al. 2020). There are some vitamin B12 analogues in human faeces (Allen and Stabler 2008). A. muciniphila might use cobalamin analogues and affect vitamin B12 metabolism in the gut. Unique cobamide metabolism may be acquired to inhabit a complex ecological niche. These metabolic crossfeeding networks are important for regulating microbial composition and host health.

There are several papers on the effect of probiotic bacteria on the growth of A. muciniphila. The administration of 
Fig. 2 The interaction between $A$. muciniphila and other bacteria

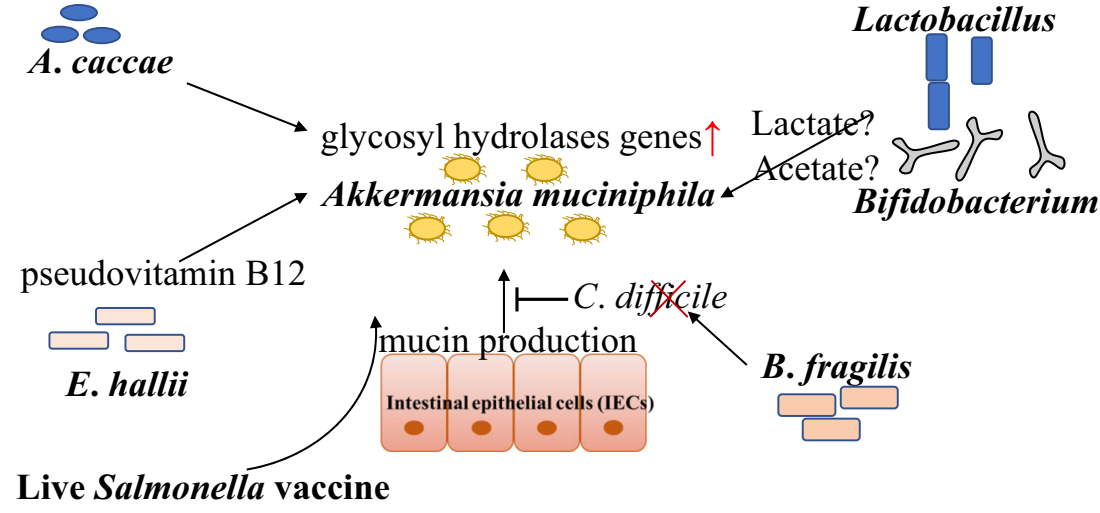

mixture composed of Lacticaseibacillus rhamnosus LMG S28148 and Bifidobacterium animalis subsp. lactis LMG P28149 improved the abundance of $A$. muciniphila associated with decreased glucose and insulin levels in obese mice (Alard et al. 2016). Acetate and lactate derived from the probiotics might stimulate the growth of $A$. muciniphila because acetate and the acetate-conjugated portion of the drug could boost the growth of $A$. muciniphila (Daisley et al. 2020). In a human study, the administration of $L$. rhamnosus HN001 and $B$. longum BB536 increases the abundance of A. muciniphila (Toscano et al. 2017). Dizman et al. demonstrated that fermented milk with $B$. animalis could improve the abundance of $A$. muciniphila in metastatic renal cell carcinoma patients (Dizman et al. 2021). These species may interact with $A$. muciniphila although the interaction mechanism is unknown.

A dose of $B$. fragilis increased the abundance of $A$. muciniphila in a mouse model of Clostridium difficile infection (Deng et al. 2018). Cross-feeding interaction via SCFAs between $A$. muciniphila and B. fragilis or the inhibition of $C$. difficile-induced apoptosis and Muc2 and ZO-1 loss in colon cells may contribute to the increase in A. muciniphila. In chicken, live Salmonella vaccine increased a mucus level resulting in an abundance of $A$. muciniphila (Redweik et al. 2019). Change in host metabolism or production of SCFAs by probiotic or vaccine effects might improve the growth of $A$. muciniphila in the gut.

\section{Interaction with diets}

A. muciniphila uses carbohydrates derived from mucin composed of fucose, galactose, $\mathrm{N}$-acetylgalactosamine (GalNAc) and N-acetylglucosamine (GlcNAc) (Ottman et al. 2017). How can other carbohydrates help A. muciniphila growth? Xylo-oligosaccharide, fructo-oligosaccharides, arabinoxylan and inulin are known as prebiotics, resulting in improved beneficial bacterial growth such as bifidobacteria and lactobacilli (McLaughlin et al. 2015). Figure 3 describes the diets or their components associated with the boost of A. muciniphila.
Long-chain arabinoxylans and inulin affect the higher production of mucin leading to an increased faecal abundance of $A$. muciniphila in humanised rats (Van den Abbeele et al. 2011). Induced-mucin production by these components is associated with the abundance of mucin-degrading $A$. muciniphila because $A$. muciniphila cannot grow on inulin. Mannanoligosaccharide also can increase the abundance of $A$. muciniphila as well as that of $B$. acidifaciens, L. gasseri and $B$. pseudolongum in high-fat diet-fed mice, resulting in the attenuation of metabolic disorders (Wang et al. 2018). In addition to oligosaccharides from dietary fibres, the abundance of A. muciniphila increased by polysaccharide from seaweed (Enteromorpha Clathrata) as well as Bifidobacterium spp. and Lactobacillus spp. (Shang et al. 2018). Gut bacteria such as Bifidobacterium and Bacteroides can degrade natural polysaccharides (Flint et al. 2008). Although it is not clear if $A$. muciniphila can degrade polysaccharides, bacterial degradation of polysaccharides may support the growth of $A$. muciniphila. A low carbohydrate diet, ketogenic diet, alters gut microbial composition with increased A. muciniphila in mice (Ma et al. 2018). The change in the gut immune system might affect $A$. muciniphila because ketogenic diets also contribute to the decreased intestinal Th17 (Ang et al. 2020). The promoted mucin production by Th17 attenuation might affect the abundance of $A$. muciniphila because the correlation between an inhibited Th17 differentiation and an increased mucin production has been indicated (Cha et al. 2010).

Plants such as vegetables, beans and herbs have plenty of phytochemicals and the effect of plants or their extractions including phytochemicals on the host health and gut microbiota has been studied (Yin et al. 2019). The increase in $A$. muciniphila was observed in high-fat/high-sucrose (HFHS)fed mice by the treatment of camu camu (Myrciaria dubia) which is a native fruit of the Amazon (Anhê et al. 2019). The treatment of camu camu affected the composition of bile acids and the increase in A. muciniphila, resulting in the prevention of obesity and metabolic syndrome. Interestingly, the abundance of $A$. muciniphila is positively correlated with the secondary bile acids such as Tauro-conjugated DCA and UDCA. 
Fig. 3 The boost of $A$. muciniphila by diets

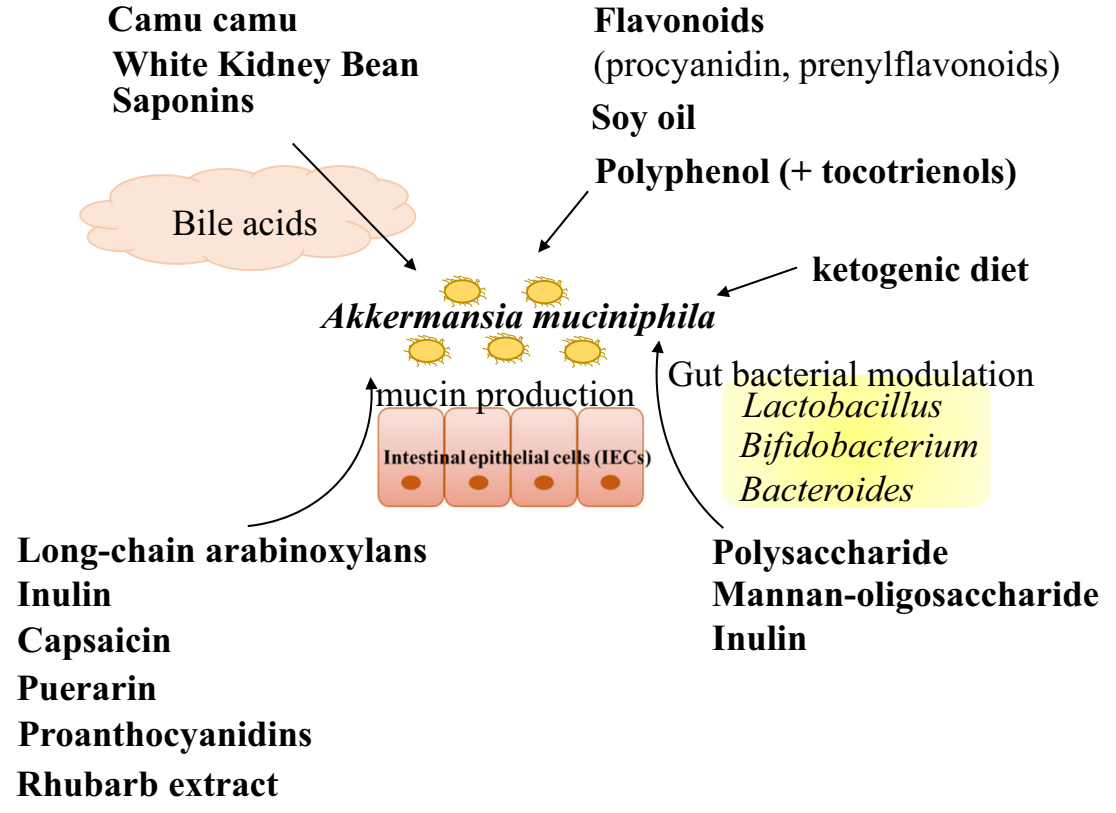

The secondary bile acids such as DCA and lithocholic acid can activate TGR5. TGR5, highly expressed in the gallbladder, brown adipose tissue and other tissues, is a bile acidresponsive receptor involved in host metabolism. The interaction between $A$. muciniphila, bile metabolism and camu camu might be related to the anti-obesity effect. The increase in $A$. muciniphila and the change in bile metabolism were observed by the treatment of white kidney bean (Phaseolus vulgaris L.) (Neil et al. 2019). Saponins from Agave salmiana also modulate bile acids and cholesterol transport systems in the liver of mice and increased A. muciniphila (Leal-Díaz et al. 2016). As described above in this review, UDCA treatment can increase the abundance of $A$. muciniphila in mice (Van den Bossche et al. 2017). Our group showed that DCA increased the growth of A. muciniphila in vitro and its bile acid-resistant metabolism (Hagi et al. 2020). These studies indicate that the change in bile acids, especially UDCA, by the treatment of camu camu could increase the abundance of $A$. muciniphila, and the interaction between secondary bile acids and A. muciniphila might affect the host bile acid metabolism. The modulation of mucus layer by diets, such as capsaicin, puerarin in the root of Pueraria lobate and wild blueberry proanthocyanidins (Rodríguez-Daza et al. 2020; Shen et al. 2017; Wang et al. 2019), may cause the increase in $A$. muciniphila. The stimulation of IECs by rhubarb extract also might contribute to the increase in A. muciniphila (Neyrinck et al. 2017). In other reports, flavonoids from apple (procyanidin) and hops (prenylflavonoids) could stimulate the growth of $A$. muciniphila leading to the improvement of metabolic syndrome (Fukizawa et al. 2020; Hamm et al. 2019; Masumoto et al. 2016). Polyphenol derived from cranberry and green tea (synergistic effect with annatto-extracted tocotrienols) is also a key component in a diet that stimulates the growth of A. muciniphila (Anhê et al. 2015; Elmassry et al. 2020). Polyphenols such as catechin have antibacterial activities (Ikigai et al. 1993). The antibacterial activity might reshape gut microbiota, which is favourable for A. muciniphila. In addition to the phytochemicals described above, soy oil also could affect the abundance of $A$. muciniphila (Patrone et al. 2018).

\section{Conclusions}

In conclusion, this article reviewed the effects of several factors such as host-derived substance, bacteria and diets on the growth of $A$. muciniphila. Mucin is a sole carbon and nitrogen source for A. muciniphila. Mucin production-stimulated factors, inulin and secondary bile acid may be related to the bloom of $A$. muciniphila. The growth of A. muciniphila also depends on a host-derived substance such as bile acids, microRNA and oligosaccharides. Gut bacteria and probiotic bacteria (especially bifidobactera and lactobacilli) also could affect the growth of $A$. muciniphila. To boost the growth of $A$. muciniphila in the gut, recent studies have investigated the effect of diet on its growth. Polysaccharides and inulin known as prebiotics could increase the abundance of $A$. muciniphila. This result may be associated with the change in gut environment by prebiotics resulting in the improvement of beneficial bacterial growth such as bifidobacteria and lactobacilli. In addition to bacterial interaction, bile acids are also considered one of the growth modulating factors of A. muciniphila because it is associated with gut bacterial composition, and secondary bile acid metabolism could be affected by diet camu camu. Altogether, these pieces of knowledge should help 
develop future treatment strategies to modulate health through increasing abundance and activity of $A$. muciniphila in the gut.

Author contribution $\mathrm{TH}$ drafted this review. $\mathrm{CB}$ revised the manuscript. Both authors read and approved the manuscript.

\section{Declarations}

Ethics approval This article does not contain any studies with human participants or animals by any of the authors.

\section{Conflict of interest The authors declare no competing interests.}

Open Access This article is licensed under a Creative Commons Attribution 4.0 International License, which permits use, sharing, adaptation, distribution and reproduction in any medium or format, as long as you give appropriate credit to the original author(s) and the source, provide a link to the Creative Commons licence, and indicate if changes were made. The images or other third party material in this article are included in the article's Creative Commons licence, unless indicated otherwise in a credit line to the material. If material is not included in the article's Creative Commons licence and your intended use is not permitted by statutory regulation or exceeds the permitted use, you will need to obtain permission directly from the copyright holder. To view a copy of this licence, visit http://creativecommons.org/licenses/by/4.0/.

\section{References}

Aakko J, Kumar H, Rautava S, Wise A, Autran C, Bode L, Isolauri E, Salminen S (2017) Human milk oligosaccharide categories define the microbiota composition in human colostrum. Benefic Microbes 8:563-567. https://doi.org/10.3920/bm2016.0185

Alard J, Lehrter V, Rhimi M, Mangin I, Peucelle V, Abraham AL, Mariadassou M, Maguin E, Waligora-Dupriet AJ, Pot B, Wolowczuk I, Grangette C (2016) Beneficial metabolic effects of selected probiotics on diet-induced obesity and insulin resistance in mice are associated with improvement of dysbiotic gut microbiota. Environ Microbiol 18:1484-1497. https://doi.org/10.1111/14622920.13181

Allen RH, Stabler SP (2008) Identification and quantitation of cobalamin and cobalamin analogues in human feces. Am J Clin Nutr 87:1324 1335. https://doi.org/10.1093/ajen/87.5.1324

Ang QY, Alexander M, Newman JC, Tian Y, Cai J, Upadhyay V, Turnbaugh JA, Verdin E, Hall KD, Leibel RL, Ravussin E, Rosenbaum M, Patterson AD, Turnbaugh PJ (2020) Ketogenic diets alter the gut microbiome resulting in decreased intestinal Th17 cells. Cell 181:1263-1275.e1216. https://doi.org/10.1016/j.cell.2020.04. 027

Anhê FF, Roy D, Pilon G, Dudonné S, Matamoros S, Varin TV, Garofalo C, Moine Q, Desjardins Y, Levy E, Marette A (2015) A polyphenolrich cranberry extract protects from diet-induced obesity, insulin resistance and intestinal inflammation in association with increased Akkermansia spp. population in the gut microbiota of mice. Gut 64: 872-883. https://doi.org/10.1136/gutjnl-2014-307142

Anhê FF, Nachbar RT, Varin TV, Trottier J, Dudonné S, Le Barz M, Feutry P, Pilon G, Barbier O, Desjardins Y, Roy D, Marette A (2019) Treatment with camu camu (Myrciaria dubia) prevents obesity by altering the gut microbiota and increasing energy expenditure in diet-induced obese mice. Gut 68:453-464. https://doi.org/10. 1136/gutjnl-2017-315565
Ansaldo E, Slayden LC, Ching KL, Koch MA, Wolf NK, Plichta DR, Brown EM, Graham DB, Xavier RJ, Moon JJ, Barton GM (2019) Akkermansia muciniphila induces intestinal adaptive immune responses during homeostasis. Science 364:1179-1184. https://doi. org/10.1126/science.aaw7479

Ballard O, Morrow AL (2013) Human milk composition: nutrients and bioactive factors. Pediatr Clin N Am 60:49-74. https://doi.org/10. 1016/j.pcl.2012.10.002

Belzer C, Chia LW, Aalvink S, Chamlagain B, Piironen V, Knol J, de Vos WM (2017) Microbial metabolic networks at the mucus layer lead to diet-independent butyrate and vitamin $\mathrm{B}(12)$ production by intestinal symbionts. mBio 8. https://doi.org/10.1128/mBio.0077017

Bergström A, Skov TH, Bahl MI, Roager HM, Christensen LB, Ejlerskov KT, Mølgaard C, Michaelsen KF, Licht TR (2014) Establishment of intestinal microbiota during early life: a longitudinal, explorative study of a large cohort of Danish infants. Appl Environ Microbiol 80:2889-2900. https://doi.org/10.1128/aem.00342-14

Berry D, Mader E, Lee TK, Woebken D, Wang Y, Zhu D, Palatinszky M, Schintlmeister A, Schmid MC, Hanson BT, Shterzer N, Mizrahi I, Rauch I, Decker T, Bocklitz T, Popp J, Gibson CM, Fowler PW, Huang WE, Wagner M (2015) Tracking heavy water (D2O) incorporation for identifying and sorting active microbial cells. Proc Natl Acad Sci U S A 112:E194-E203. https://doi.org/10.1073/pnas. 1420406112

Cha HR, Chang SY, Chang JH, Kim JO, Yang JY, Kim CH, Kweon MN (2010) Downregulation of Th17 cells in the small intestine by disruption of gut flora in the absence of retinoic acid. J Immunol 184: 6799-6806. https://doi.org/10.4049/jimmunol.0902944

Chen J, Chia N, Kalari KR, Yao JZ, Novotna M, Paz Soldan MM, Luckey DH, Marietta EV, Jeraldo PR, Chen X, Weinshenker BG, Rodriguez M, Kantarci OH, Nelson H, Murray JA, Mangalam AK (2016) Multiple sclerosis patients have a distinct gut microbiota compared to healthy controls. Sci Rep 6:28484. https://doi.org/10. 1038/srep28484

Chia LW, Hornung BVH, Aalvink S, Schaap PJ, de Vos WM, Knol J, Belzer C (2018) Deciphering the trophic interaction between Akkermansia muciniphila and the butyrogenic gut commensal Anaerostipes caccae using a metatranscriptomic approach. Antonie Van Leeuwenhoek 111:859-873. https://doi.org/10.1007/ s10482-018-1040-x

Crouch LI, Liberato MV, Urbanowicz PA, Baslé A, Lamb CA, Stewart CJ, Cooke K, Doona M, Needham S, Brady RR, Berrington JE, Madunic K, Wuhrer M, Chater P, Pearson JP, Glowacki R, Martens EC, Zhang F, Linhardt RJ, Spencer DIR, Bolam DN (2020) Prominent members of the human gut microbiota express endo-acting $\mathrm{O}$-glycanases to initiate mucin breakdown. Nat Commun 11:4017. https://doi.org/10.1038/s41467-020-17847-5

Dabke K, Hendrick G, Devkota S (2019) The gut microbiome and metabolic syndrome. J Clin Invest 129:4050-4057. https://doi.org/10. 1172/jci129194

Daisley BA, Chanyi RM, Abdur-Rashid K, Al KF, Gibbons S, Chmiel JA, Wilcox H, Reid G, Anderson A, Dewar M, Nair SM, Chin J, Burton JP (2020) Abiraterone acetate preferentially enriches for the gut commensal Akkermansia muciniphila in castrate-resistant prostate cancer patients. Nat Commun 11:4822. https://doi.org/10.1038/ s41467-020-18649-5

Daniel H, Gholami AM, Berry D, Desmarchelier C, Hahne H, Loh G, Mondot S, Lepage P, Rothballer M, Walker A, Böhm C, Wenning M, Wagner M, Blaut M, Schmitt-Kopplin P, Kuster B, Haller D, Clavel T (2014) High-fat diet alters gut microbiota physiology in mice. ISME J 8:295-308. https://doi.org/10.1038/ismej.2013.155

David LA, Maurice CF, Carmody RN, Gootenberg DB, Button JE, Wolfe BE, Ling AV, Devlin AS, Varma Y, Fischbach MA, Biddinger SB, Dutton RJ, Turnbaugh PJ (2014) Diet rapidly and reproducibly 
alters the human gut microbiome. Nature 505:559-563. https://doi. org/10.1038/nature12820

Davis JA, Collier F, Mohebbi M, Stuart AL, Loughman A, Pasco JA, Jacka FN (2020) Obesity, Akkermansia muciniphila, and proton pump inhibitors: is there a link? Obes Res Clin Pract 14:524-530. https://doi.org/10.1016/j.orcp.2020.10.006

Deng H, Yang S, Zhang Y, Qian K, Zhang Z, Liu Y, Wang Y, Bai Y, Fan $\mathrm{H}$, Zhao X, Zhi F (2018) Bacteroides fragilis prevents Clostridium difficile infection in a mouse model by restoring gut barrier and microbiome regulation. Front Microbiol 9:2976. https://doi.org/10. 3389/fmicb.2018.02976

Depommier C, Everard A, Druart C, Plovier H, Van Hul M, Vieira-Silva S, Falony G, Raes J, Maiter D, Delzenne NM, de Barsy M, Loumaye A, Hermans MP, Thissen JP, de Vos WM, Cani PD (2019) Supplementation with Akkermansia muciniphila in overweight and obese human volunteers: a proof-of-concept exploratory study. Nat Med 25:1096-1103. https://doi.org/10.1038/s41591-019-0495-2

Derrien M, Vaughan EE, Plugge CM, de Vos WM (2004) Akkermansia muciniphila gen. nov., sp. nov., a human intestinal mucin-degrading bacterium. Int J Syst Evol Microbiol 54:1469-1476. https://doi.org/ 10.1099/ijs.0.02873-0

Dizman N, Hsu J, Bergerot PG, Gillece JD, Folkerts M, Reining L, Trent J, Highlander SK, Pal SK (2021) Randomized trial assessing impact of probiotic supplementation on gut microbiome and clinical outcome from targeted therapy in metastatic renal cell carcinoma. Cancer Med 10:79-86. https://doi.org/10.1002/cam4.3569

Duran-Sanchon S, Moreno L, Augé JM, Serra-Burriel M, Cuatrecasas M, Moreira L, Martín A, Serradesanferm A, Pozo À, Costa R, Lacy A, Pellisé M, Lozano JJ, Gironella M, Castells A (2020) Identification and validation of microRNA profiles in fecal samples for detection of colorectal cancer. Gastroenterology 158:947-957.e944. https:// doi.org/10.1053/j.gastro.2019.10.005

Earley H, Lennon G, Balfe Á, Coffey JC, Winter DC, O'Connell PR (2019) The abundance of Akkermansia muciniphila and its relationship with sulphated colonic mucins in health and ulcerative colitis. Sci Rep 9:15683. https://doi.org/10.1038/s41598-019-51878-3

Elmassry MM, Chung E, Cao JJ, Hamood AN, Shen CL (2020) Osteoprotective effect of green tea polyphenols and annattoextracted tocotrienol in obese mice is associated with enhanced microbiome vitamin $\mathrm{K}(2)$ biosynthetic pathways. J Nutr Biochem 86:108492. https://doi.org/10.1016/j.jnutbio.2020.108492

Everard A, Belzer C, Geurts L, Ouwerkerk JP, Druart C, Bindels LB, Guiot Y, Derrien M, Muccioli GG, Delzenne NM, de Vos WM, Cani PD (2013) Cross-talk between Akkermansia muciniphila and intestinal epithelium controls diet-induced obesity. Proc Natl Acad Sci U S A 110:9066-9071. https://doi.org/10.1073/pnas. 1219451110

Flint HJ, Bayer EA, Rincon MT, Lamed R, White BA (2008) Polysaccharide utilization by gut bacteria: potential for new insights from genomic analysis. Nat Rev Microbiol 6:121-131. https://doi. org $/ 10.1038 /$ nrmicro 1817

Fukizawa S, Yamashita M, Wakabayashi KI, Fujisaka S, Tobe K, Nonaka Y, Murayama N (2020) Anti-obesity effect of a hopderived prenylflavonoid isoxanthohumol in a high-fat diet-induced obese mouse model. Biosci Microbiota Food Health 39:175-182. https://doi.org/10.12938/bmfh.2019-040

Gallo A, Tandon M, Alevizos I, Illei GG (2012) The majority of microRNAs detectable in serum and saliva is concentrated in exosomes. PLoS One 7:e30679. https://doi.org/10.1371/journal. pone. 0030679

Geerlings SY, Kostopoulos I, de Vos WM, Belzer C (2018) Akkermansia muciniphila in the human gastrointestinal tract: when, where, and how? Microorganisms 6. https://doi.org/10.3390/ microorganisms 6030075

Gennarino VA, Sardiello M, Avellino R, Meola N, Maselli V, Anand S, Cutillo L, Ballabio A, Banfi S (2009) MicroRNA target prediction by expression analysis of host genes. Genome Res 19:481-490. https://doi.org/10.1101/gr.084129.108

Gentile CL, Weir TL (2018) The gut microbiota at the intersection of diet and human health. Science 362:776-780. https://doi.org/10.1126/ science.aau5812

Giannoudaki E, Hernandez-Santana YE, Mulfaul K, Doyle SL, Hams E, Fallon PG, Mat A, O'Shea D, Kopf M, Hogan AE, Walsh PT (2019) Interleukin-36 cytokines alter the intestinal microbiome and can protect against obesity and metabolic dysfunction. Nat Commun 10:4003. https://doi.org/10.1038/s41467-019-11944-w

Hagi T, Geerlings SY, Nijsse B, Belzer C (2020) The effect of bile acids on the growth and global gene expression profiles in Akkermansia muciniphila. Appl Microbiol Biotechnol 104:10641-10653. https:// doi.org/10.1007/s00253-020-10976-3

Hamm AK, Manter DK, Kirkwood JS, Wolfe LM, Cox-York K, Weir TL (2019) The effect of hops (Humulus lupulus L.) extract supplementation on weight gain, adiposity and intestinal function in ovariectomized mice. Nutrients 11. https://doi.org/10.3390/nu11123004

Hansen CH, Krych L, Nielsen DS, Vogensen FK, Hansen LH, Sørensen SJ, Buschard K, Hansen AK (2012) Early life treatment with vancomycin propagates Akkermansia muciniphila and reduces diabetes incidence in the NOD mouse. Diabetologia 55:2285-2294. https:// doi.org/10.1007/s00125-012-2564-7

Ikigai H, Nakae T, Hara Y, Shimamura T (1993) Bactericidal catechins damage the lipid bilayer. Biochim Biophys Acta 1147:132-136. https://doi.org/10.1016/0005-2736(93)90323-r

Jackson MA, Goodrich JK, Maxan ME, Freedberg DE, Abrams JA, Poole AC, Sutter JL, Welter D, Ley RE, Bell JT, Spector TD, Steves CJ (2016) Proton pump inhibitors alter the composition of the gut microbiota. Gut 65:749-756. https://doi.org/10.1136/gutjnl2015-310861

Kao HF, Wang YC, Tseng HY, Wu LS, Tsai HJ, Hsieh MH, Chen PC, Kuo WS, Liu LF, Liu ZG, Wang JY (2020) Goat milk consumption enhances innate and adaptive immunities and alleviates allergeninduced airway inflammation in offspring mice. Front Immunol 11:184. https://doi.org/10.3389/fimmu.2020.00184

Kirmiz N, Galindo K, Cross KL, Luna E, Rhoades N, Podar M, Flores GE (2020) Comparative genomics guides elucidation of vitamin $\mathrm{B}(12)$ biosynthesis in novel human-associated Akkermansia strains. Appl Environ Microbiol 86. https://doi.org/10.1128/aem.02117-19

Kostopoulos I, Elzinga J, Ottman N, Klievink JT, Blijenberg B, Aalvink S, Boeren S, Mank M, Knol J, de Vos WM, Belzer C (2020) Akkermansia muciniphila uses human milk oligosaccharides to thrive in the early life conditions in vitro. Sci Rep 10:14330. https://doi.org/10.1038/s41598-020-71113-8

Kroh EM, Parkin RK, Mitchell PS, Tewari M (2010) Analysis of circulating microRNA biomarkers in plasma and serum using quantitative reverse transcription-PCR (qRT-PCR). Methods 50:298-301. https://doi.org/10.1016/j.ymeth.2010.01.032

Lawson MAE, O'Neill IJ, Kujawska M, Gowrinadh Javvadi S, Wijeyesekera A, Flegg Z, Chalklen L, Hall LJ (2020) Breast milkderived human milk oligosaccharides promote Bifidobacterium interactions within a single ecosystem. ISME J 14:635-648. https:// doi.org/10.1038/s41396-019-0553-2

Leal-Díaz AM, Noriega LG, Torre-Villalvazo I, Torres N, AlemánEscondrillas G, López-Romero P, Sánchez-Tapia M, AguilarLópez M, Furuzawa-Carballeda J, Velázquez-Villegas LA, AvilaNava A, Ordáz G, Gutiérrez-Uribe JA, Serna-Saldivar SO, Tovar AR (2016) Aguamiel concentrate from Agave salmiana and its extracted saponins attenuated obesity and hepatic steatosis and increased Akkermansia muciniphila in C57BL6 mice. Sci Rep 6: 34242. https://doi.org/10.1038/srep34242

Liu S, da Cunha AP, Rezende RM, Cialic R, Wei Z, Bry L, Comstock LE, Gandhi R, Weiner HL (2016) The host shapes the gut microbiota via fecal microRNA. Cell Host Microbe 19:32-43. https://doi.org/10. 1016/j.chom.2015.12.005 
Liu S, Rezende RM, Moreira TG, Tankou SK, Cox LM, Wu M, Song A, Dhang FH, Wei Z, Costamagna G, Weiner HL (2019) Oral administration of miR-30d from feces of MS patients suppresses MS-like symptoms in mice by expanding Akkermansia muciniphila. Cell Host Microbe 26:779-794.e778. https://doi.org/10.1016/j.chom. 2019.10.008

Louis P, Flint HJ (2017) Formation of propionate and butyrate by the human colonic microbiota. Environ Microbiol 19:29-41. https://doi. org/10.1111/1462-2920.13589

Ma D, Wang AC, Parikh I, Green SJ, Hoffman JD, Chlipala G, Murphy MP, Sokola BS, Bauer B, Hartz AMS, Lin AL (2018) Ketogenic diet enhances neurovascular function with altered gut microbiome in young healthy mice. Sci Rep 8:6670. https://doi.org/10.1038/ s41598-018-25190-5

Makki K, Deehan EC, Walter J, Bäckhed F (2018) The impact of dietary fiber on gut microbiota in host health and disease. Cell Host Microbe 23:705-715. https://doi.org/10.1016/j.chom.2018.05.012

Marchesi JR, Adams DH, Fava F, Hermes GD, Hirschfield GM, Hold G, Quraishi MN, Kinross J, Smidt H, Tuohy KM, Thomas LV, Zoetendal EG, Hart A (2016) The gut microbiota and host health: a new clinical frontier. Gut 65:330-339. https://doi.org/10.1136/ gutjnl-2015-309990

Masumoto S, Terao A, Yamamoto Y, Mukai T, Miura T, Shoji T (2016) Non-absorbable apple procyanidins prevent obesity associated with gut microbial and metabolomic changes. Sci Rep 6:31208. https:// doi.org/10.1038/srep31208

McLaughlin HP, Motherway MO, Lakshminarayanan B, Stanton C, Paul Ross R, Brulc J, Menon R, O'Toole PW, van Sinderen D (2015) Carbohydrate catabolic diversity of bifidobacteria and lactobacilli of human origin. Int J Food Microbiol 203:109-121. https://doi.org/10. 1016/j.ijfoodmicro.2015.03.008

McLoughlin K, Schluter J, Rakoff-Nahoum S, Smith AL, Foster KR (2016) Host selection of microbiota via differential adhesion. Cell Host Microbe 19:550-559. https://doi.org/10.1016/j.chom.2016.02. 021

Mirza AH, Kaur S, Nielsen LB, Størling J, Yarani R, Roursgaard M, Mathiesen ER, Damm P, Svare J, Mortensen HB, Pociot F (2019) Breast milk-derived extracellular vesicles enriched in exosomes from mothers with type 1 diabetes contain aberrant levels of microRNAs. Front Immunol 10:2543. https://doi.org/10.3389/ fimmu.2019.02543

Mok KC, Sokolovskaya OM, Nicolas AM, Hallberg ZF, Deutschbauer A, Carlson HK, Taga ME (2020) Identification of a novel cobamide remodeling enzyme in the beneficial human gut bacterium Akkermansia muciniphila. mBio:11. https://doi.org/10.1128/mBio. 02507-20

Moossavi S, Sepehri S, Robertson B, Bode L, Goruk S, Field CJ, Lix LM, de Souza RJ, Becker AB, Mandhane PJ, Turvey SE, Subbarao P, Moraes TJ, Lefebvre DL, Sears MR, Khafipour E, Azad MB (2019) Composition and variation of the human milk microbiota are influenced by maternal and early-life factors. Cell Host Microbe 25:324 335.e324. https://doi.org/10.1016/j.chom.2019.01.011

Mu C, Zhu W (2019) Antibiotic effects on gut microbiota, metabolism, and beyond. Appl Microbiol Biotechnol 103:9277-9285. https:// doi.org/10.1007/s00253-019-10165-x

Muller PA, Matheis F, Schneeberger M, Kerner Z, Jové V, Mucida D (2020) Microbiota-modulated CART(+) enteric neurons autonomously regulate blood glucose. Science 370:314-321. https://doi. org/10.1126/science.abd6176

Neil ES, McGinley JN, Fitzgerald VK, Lauck CA, Tabke JA, StreeterMcDonald MR, Yao L, Broeckling CD, Weir TL, Foster MT, Thompson HJ (2019) White kidney bean (Phaseolus vulgaris L.) consumption reduces fat accumulation in a polygenic mouse model of obesity. Nutrients 11. https://doi.org/10.3390/nu11112780

Neyrinck AM, Etxeberria U, Taminiau B, Daube G, Van Hul M, Everard A, Cani PD, Bindels LB, Delzenne NM (2017) Rhubarb extract prevents hepatic inflammation induced by acute alcohol intake, an effect related to the modulation of the gut microbiota. Mol Nutr Food Res 61. https://doi.org/10.1002/mnfr.201500899

O'Brien J, Hayder H, Zayed Y, Peng C (2018) Overview of microRNA biogenesis, mechanisms of actions, and circulation. Front Endocrinol (Lausanne) 9:402. https://doi.org/10.3389/fendo.2018. 00402

Ottman N, Davids M, Suarez-Diez M, Boeren S, Schaap PJ, Martins Dos Santos VAP, Smidt H, Belzer C, de Vos WM (2017) Genome-scale model and omics analysis of metabolic capacities of Akkermansia muciniphila reveal a preferential mucin-degrading lifestyle. Appl Environ Microbiol 83. https://doi.org/10.1128/aem.01014-17

Ouwerkerk JP, van der Ark KCH, Davids M, Claassens NJ, Finestra TR, de Vos WM, Belzer C (2016) Adaptation of Akkermansia muciniphila to the oxic-anoxic interface of the mucus layer. Appl Environ Microbiol 82:6983-6993. https://doi.org/10.1128/aem. 01641-16

Pandi-Perumal SR, Zisapel N, Srinivasan V, Cardinali DP (2005) Melatonin and sleep in aging population. Exp Gerontol 40:911925. https://doi.org/10.1016/j.exger.2005.08.009

Patrone V, Minuti A, Lizier M, Miragoli F, Lucchini F, Trevisi E, Rossi F, Callegari ML (2018) Differential effects of coconut versus soy oil on gut microbiota composition and predicted metabolic function in adult mice. BMC Genomics 19:808. https://doi.org/10.1186/ s12864-018-5202-z

Plovier H, Everard A, Druart C, Depommier C, Van Hul M, Geurts L, Chilloux J, Ottman N, Duparc T, Lichtenstein L, Myridakis A, Delzenne NM, Klievink J, Bhattacharjee A, van der Ark KC, Aalvink S, Martinez LO, Dumas ME, Maiter D, Loumaye A, Hermans MP, Thissen JP, Belzer C, de Vos WM, Cani PD (2017) A purified membrane protein from Akkermansia muciniphila or the pasteurized bacterium improves metabolism in obese and diabetic mice. Nat Med 23:107-113. https://doi.org/10.1038/nm.4236

Putignani L, Del Chierico F, Petrucca A, Vernocchi P, Dallapiccola B (2014) The human gut microbiota: a dynamic interplay with the host from birth to senescence settled during childhood. Pediatr Res 76:210. https://doi.org/10.1038/pr.2014.49

Redweik GAJ, Daniels K, Severin AJ, Lyte M, Mellata M (2019) Oral treatments with probiotics and live Salmonella vaccine induce unique changes in gut neurochemicals and microbiome in chickens. Front Microbiol 10:3064. https://doi.org/10.3389/fmicb.2019. 03064

Rodríguez-Daza MC, Daoust L, Boutkrabt L, Pilon G, Varin T, Dudonné S, Levy É, Marette A, Roy D, Desjardins Y (2020) Wild blueberry proanthocyanidins shape distinct gut microbiota profile and influence glucose homeostasis and intestinal phenotypes in high-fat highsucrose fed mice. Sci Rep 10:2217. https://doi.org/10.1038/s41598020-58863-1

Rutsch A, Kantsjö JB, Ronchi F (2020) The gut-brain axis: how microbiota and host inflammasome influence brain physiology and pathology. Front Immunol 11:604179. https://doi.org/10.3389/fimmu. 2020.604179

Santacruz A, Collado MC, García-Valdés L, Segura MT, Martín-Lagos JA, Anjos T, Martí-Romero M, Lopez RM, Florido J, Campoy C, Sanz Y (2010) Gut microbiota composition is associated with body weight, weight gain and biochemical parameters in pregnant women. Br J Nutr 104:83-92. https://doi.org/10.1017/ s0007114510000176

Schneeberger M, Everard A, Gómez-Valadés AG, Matamoros S, Ramírez S, Delzenne NM, Gomis R, Claret M, Cani PD (2015) Akkermansia muciniphila inversely correlates with the onset of inflammation, altered adipose tissue metabolism and metabolic disorders during obesity in mice. Sci Rep 5:16643. https://doi.org/10. 1038/srep 16643 
Servin AL (2004) Antagonistic activities of lactobacilli and bifidobacteria against microbial pathogens. FEMS Microbiol Rev 28:405-440. https://doi.org/10.1016/j.femsre.2004.01.003

Shang Q, Wang Y, Pan L, Niu Q, Li C, Jiang H, Cai C, Hao J, Li G, Yu G (2018) Dietary polysaccharide from Enteromorpha clathrata modulates gut microbiota and promotes the growth of Akkermansia muciniphila, Bifidobacterium spp. and Lactobacillus spp. Mar Drugs 16. https://doi.org/10.3390/md16050167

Shen W, Shen M, Zhao X, Zhu H, Yang Y, Lu S, Tan Y, Li G, Li M, Wang J, Hu F, Le S (2017) Anti-obesity effect of capsaicin in mice fed with high-fat diet is associated with an increase in population of the gut bacterium Akkermansia muciniphila. Front Microbiol 8:272. https://doi.org/10.3389/fmicb.2017.00272

Shin NR, Lee JC, Lee HY, Kim MS, Whon TW, Lee MS, Bae JW (2014) An increase in the Akkermansia spp. population induced by metformin treatment improves glucose homeostasis in diet-induced obese mice. Gut 63:727-735. https://doi.org/10.1136/gutjnl-2012-303839

Song S, Byrd JC, Koo JS, Bresalier RS (2005) Bile acids induce MUC2 overexpression in human colon carcinoma cells. Cancer 103:16061614. https://doi.org/10.1002/cncr.21015

Toscano M, De Grandi R, Stronati L, De Vecchi E, Drago L (2017) Effect of Lactobacillus rhamnosus HN001 and Bifidobacterium longum BB536 on the healthy gut microbiota composition at phyla and species level: a preliminary study. World J Gastroenterol 23:26962704. https://doi.org/10.3748/wjg.v23.i15.2696

van Best N, Rolle-Kampczyk U, Schaap FG, Basic M, Olde Damink SWM, Bleich A, Savelkoul PHM, von Bergen M, Penders J, Hornef MW (2020) Bile acids drive the newborn's gut microbiota maturation. Nat Commun 11:3692. https://doi.org/10.1038/s41467020-17183-8

Van den Abbeele P, Gérard P, Rabot S, Bruneau A, El Aidy S, Derrien M, Kleerebezem M, Zoetendal EG, Smidt H, Verstraete W, Van de Wiele T, Possemiers S (2011) Arabinoxylans and inulin differentially modulate the mucosal and luminal gut microbiota and mucindegradation in humanized rats. Environ Microbiol 13:2667-2680. https://doi.org/10.1111/j.1462-2920.2011.02533.x

Van den Bossche L, Hindryckx P, Devisscher L, Devriese S, Van Welden S, Holvoet T, Vilchez-Vargas R, Vital M, Pieper DH, Vanden Bussche J, Vanhaecke L, Van de Wiele T, De Vos M, Laukens D (2017) Ursodeoxycholic acid and its taurine- or glycine-conjugated species reduce colitogenic dysbiosis and equally suppress experimental colitis in mice. Appl Environ Microbiol 83:83. https://doi. org/10.1128/aem.02766-16
Veiga P, Pons N, Agrawal A, Oozeer R, Guyonnet D, Brazeilles R, Faurie JM, van Hylckama Vlieg JE, Houghton LA, Whorwell PJ, Ehrlich SD, Kennedy SP (2014) Changes of the human gut microbiome induced by a fermented milk product. Sci Rep 4:6328. https://doi. org $/ 10.1038 /$ srep06328

Vogt NM, Kerby RL, Dill-McFarland KA, Harding SJ, Merluzzi AP, Johnson SC, Carlsson CM, Asthana S, Zetterberg H, Blennow K, Bendlin BB, Rey FE (2017) Gut microbiome alterations in Alzheimer's disease. Sci Rep 7:13537. https://doi.org/10.1038/ s41598-017-13601-y

Wahlström A, Sayin SI, Marschall HU, Bäckhed F (2016) Intestinal crosstalk between bile acids and microbiota and its impact on host metabolism. Cell Metab 24:41-50. https://doi.org/10.1016/j.cmet. 2016.05.005

Wang H, Zhang X, Wang S, Li H, Lu Z, Shi J, Xu Z (2018) Mannanoligosaccharide modulates the obesity and gut microbiota in high-fat diet-fed mice. Food Funct 9:3916-3929. https://doi.org/10.1039/ c8fo00209f

Wang L, Wu Y, Zhuang L, Chen X, Min H, Song S, Liang Q, Li AD, Gao Q (2019) Puerarin prevents high-fat diet-induced obesity by enriching Akkermansia muciniphila in the gut microbiota of mice. PLoS One 14:e0218490. https://doi.org/10.1371/journal.pone. 0218490

Wittkopf N, Neurath MF, Becker C (2014) Immune-epithelial crosstalk at the intestinal surface. J Gastroenterol 49:375-387. https://doi.org/ 10.1007/s00535-013-0929-4

Wu H, Esteve E, Tremaroli V, Khan MT, Caesar R, Mannerås-Holm L, Ståhlman M, Olsson LM, Serino M, Planas-Fèlix M, Xifra G, Mercader JM, Torrents D, Burcelin R, Ricart W, Perkins R, Fernàndez-Real JM, Bäckhed F (2017) Metformin alters the gut microbiome of individuals with treatment-naive type 2 diabetes, contributing to the therapeutic effects of the drug. Nat Med 23: 850-858. https://doi.org/10.1038/nm.4345

Xu P, Wang J, Hong F, Wang S, Jin X, Xue T, Jia L, Zhai Y (2017) Melatonin prevents obesity through modulation of gut microbiota in mice. J Pineal Res 62. https://doi.org/10.1111/jpi.12399

Yin R, Kuo HC, Hudlikar R, Sargsyan D, Li S, Wang L, Wu R, Kong AN (2019) Gut microbiota, dietary phytochemicals and benefits to human health. Curr Pharmacol Rep 5:332-344. https://doi.org/10. 1007/s40495-019-00196-3

Publisher's note Springer Nature remains neutral with regard to jurisdictional claims in published maps and institutional affiliations. 